\title{
Blastocoel cavity formation by preimplantation rat embryos in the presence of cyanide and other inhibitors of oxidative phosphorylation
}

\author{
D. R. Brison* and H. J. Leese \\ Department of Biology, University of York, Heslington, York YO1 5DD, UK
}

\begin{abstract}
The role of oxidative phosphorylation in blastocoel development in rats was determined by culturing morula stage embryos for $24 \mathrm{~h}$ in the presence of three inhibitors of ATP generation: cyanide, antimycin-A and 2,4-dinitrophenol (DNP). Rat morulae could form blastocysts in concentrations of cyanide that are toxic to the embryos of other mammals. Similar results were obtained with antimycin-A and DNP, although DNP reduced the number of blastocysts that formed. A non-invasive ultramicrofluorometric assay was used on single blastocysts and the glycolytic pathway was shown to be stimulated in the presence of these inhibitors. These results suggest that, uniquely among preimplantation embryos studied, the developing rat blastocyst does not have an absolute requirement for oxidative phosphorylation but may be able to compensate by increasing the amount of glucose consumed and metabolized by glycolysis. This pattern of metabolism may be related to the changing maternal environment during development, with blastocoel cavity formation and implantation taking place in increasingly anoxic conditions.
\end{abstract}

\section{Introduction}

The preimplantation period of development in the rat lasts for 5 days after fertilization; during this time the embryo is a free-living structure with a high requirement for energy, particularly during the critical differentiative event of blastocoel cavity formation (Leese, 1991). The embryos of the most widely studied species, the mouse, are thought to generate ATP during the preimplantation period via two major metabolic pathways: the oxidation of substrates via the tricarboxylic acid (TCA) cycle/oxidative phosphorylation, and the breakdown of glucose via glycolysis to lactate (Brinster, 1967a; Wales, 1969; Biggers and Stern, 1973; Leese, 1991). In mouse blastocysts freshly flushed from the reproductive tract, only $33-44 \%$ of the glucose consumed is accounted for by lactate production (Gardner and Leese, 1990; Gardner and Sakkas, 1993). As the yields of ATP from oxidative phosphorylation and glycolysis are, respectively, 38 and 2 molecules per molecule of glucose, it may be concluded that in the preimplantation mouse embryo, as in most adult mammalian cells, ATP generation from oxidative phosphorylation is quantitatively much more significant than that from glycolysis. Mouse embryos, in common with most mammalian cells, are therefore highly sensitive to inhibitors of oxidative phosphorylation such as cyanide (Thomson, 1967).

However, there is evidence that developing rat blastocysts may exhibit a different pattern of energy metabolism, as they convert glucose quantitatively to lactate (Brison and Leese, 1991), and do not oxidize significant amounts of glucose via

*Present address and correspondence: Department of Biology, University of Pennsylvania, Philadelphia, PA 19104-6018, USA.

Received 27 September 1993 the TCA cycle (Dufrasnes et al., 1993). The question therefore arises as to what extent rat embryos depend on oxidative phosphorylation to generate the ATP required for development. We have addressed this question by examining the effect of inhibitors of oxidative phosphorylation on blastocyst formation and metabolism.

\section{Materials and Methods}

\section{Embryo generation and culture}

Rat embryos were generated and cultured as described by Brison and Leese (1991, 1993). Immature (28-30 days old) random-bred female rats of the Wistar strain were given single injections of non-superovulatory doses of 5 iu pregnant mares' serum gonadotrophin (PMSG: Folligon; Intervet, Cambridge, UK), followed $45-50 \mathrm{~h}$ later by 5 iu hCG (Chorulon; Intervet) to synchronize the timing of ovulation. They were immediately placed singly with males overnight to mate. Female mice, 6-8 weeks of age, of the inbred strain $\mathrm{CBA} / \mathrm{Ca} \times \mathrm{C} 57 \mathrm{BL} / 6$ were superovulated with 5 iu PMSG, followed $48 \mathrm{~h}$ later by $5 \mathrm{iu}$ hCG and also mated singly with males.

Rat embryos were recovered at the two- to four-cell or morula stage by flushing the oviducts with $\mathrm{H} 6$, a Hepesbuffered T6 medium (Wood and Whittingham, 1981), on day 2 or mid-day 4 after mating, respectively. Blastocysts were recovered by flushing the uterus on day 5. Embryos were cultured in a modification of T6 medium (Wood and Whittingham, 1981; Brison and Leese, 1991) containing $1.0 \mathrm{mmol}$ glucose $\mathrm{I}^{-1}, 2.0 \mathrm{mmol}(\mathrm{D}+\mathrm{L})$ lactate $\mathrm{I}^{-1}$ and $0.25 \mathrm{mmol}$ pyruvate $\mathrm{I}^{-1}$, adjusted to an osmolarity of 
$258 \pm 4$ mosmol kg ${ }^{-1}$, and supplemented with $1 \mathrm{~g}$ polyvinyl alcohol $\mathrm{l}^{-1}$. Mouse morulae were recovered from the oviducts on day 3, and cultured in a modified medium M16

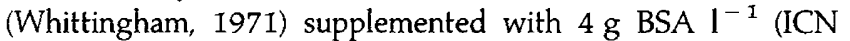
Immunobiologicals, High Wycombe, Bucks). Embryos of both species were cultured in $20 \mu \mathrm{l}$ drops of medium under light paraffin oil (BDH, Poole, Dorset) at $37^{\circ} \mathrm{C}$ in a humidified atmosphere of $5 \% \mathrm{CO}_{2}$ in air.

\section{Oxidative phosphorylation inhibitors}

All three oxidative phosphorylation inhibitors were prepared on the day of the experiment as $10 \times$ stock solutions in T6, and serially diluted in $20 \mu \mathrm{l}$ culture drops of T6 preequilibrated overnight. Cyanide was dissolved in T6 at a concentration of $10 \mathrm{mmol} \mathrm{I}^{-1}$. Antimycin-A was initially dissolved in ethanol, diluted with medium T6 to a concentration of $20 \mathrm{mg} \mathrm{I}^{-1}$, and sonicated to yield a clear solution. The maximum final concentration of ethanol was $0.02 \%$. 2,4-Dinitrophenol (DNP) was dissolved in T6 at a concentration of $10 \mathrm{mmol} \mathrm{l}^{-1}$, and sonicated. None of the inhibitor concentrations used altered the osmolarity or $\mathrm{pH}$ of the medium significantly. Control drops of T6 were treated by adding an equivalent amount of T6 medium, containing ethanol if appropriate.

Fresh stocks of inhibitors were used for each replicate of each experiment. Two sources of cyanide, $\mathrm{NaCN}$ and $\mathrm{KCN}$, were used, with identical results, and two sources of Antimycin-A (Sigma A-2006 and A-8674), also with identical results.

\section{Morphological assessment}

Morulae were cultured for $24 \mathrm{~h}$ from day 4 to day 5 after fertilization in the absence or presence of the inhibitors. At the end of this period they were scored as compacting morulae, early blastocysts (if the blastocoel cavity was less than fully formed), and blastocysts (if they were fully expanded). The total numbers of cells of blastocysts were determined using the polynucleotide-specific fluorochrome bis-benzamide to label cell nuclei (Handyside and Hunter, 1984). Embryos were classed as morphologically normal if, in the case of blastocysts, they remained fully expanded, or in the case of morula and earlier cleavage stages, if the cytoplasm was clear and cell membranes intact. Embryos were scored as degenerate if the blastocysts collapsed, or if blastomeres showed disrupted cell membranes and dark, condensed cytoplasm.

\section{Non-invasive assays}

Glucose consumption and lactate production by the same embryo were measured non-invasively using the ultramicrofluorometric technique described previously (Leese and Barton 1984; Gardner and Leese, 1990; Brison and Leese, 1991). Day 5 blastocysts, of a similar size and degree of expansion, freshly flushed from the uterus, were incubated individually for $2 \mathrm{~h}$ in $48.1 \mathrm{nl}$ drops of T6 $\pm \mathrm{KCN}$ or DNP. The microdrops were stored under paraffin oil at $-20^{\circ} \mathrm{C}$ until analysis. Glucose consumption and lactate production were determined for each blastocyst by comparing their concentrations in the spent microdrops to those in non-embryo containing control drops in the same dish. The inhibitors used did not affect the assays and in any case were included in the control drops for each series.

\section{Expression of results and statistical analysis}

The development of morulae in culture was expressed as the percentage reaching each developmental stage. Differences between treatments were tested for statistical significance by $\chi^{2}$ analysis. Differences in blastocyst cell numbers and glucose consumption/lactate production were tested for significance by Student's $t$ test.

\section{Results}

\section{Embryo culture experiments}

The role of oxidative phosphorylation in blastocoel development in rats was determined by culturing embryos from the morula stage in various concentrations of three known inhibitors of oxidative phosphorylation: cyanide, antimycin-A and 2,4-dinitrophenol (Slater, 1963, 1967). Each culture experiment was carried out between three and five times, and similar results were obtained for each replicate, which were then pooled. Cyanide had no significant effect on the proportions of morulae reaching each developmental stage (Table 1 and Fig. 1) and the blastocysts that formed were of normal morphology. Cyanide $\left(1.0 \mathrm{mmol}^{-1}\right)$ caused a slight reduction in the number of cells, suggesting a minor effect on cell division (Table 1 ). Antimycin-A had no significant effect on development, and no effect on final blastocyst cell number, in a concentration range that inhibits respiration in rabbit blastocysts (Benos and Balaban, 1983) and cultured cells (Gauthier et al., 1990). No effect on development was seen in concentrations up to $0.1 \mathrm{mmol}$ DNP $1^{-1}$, which effectively uncouple electron transport from ATP production in rabbit blastocysts (Benos and Balaban, 1980) and other cells (Slater, 1963). However, in $1.0 \mathrm{mmol} \mathrm{DNP} 1^{-1}$, development was reduced, although $38 \%$ of morulae still formed blastocysts, which contained fewer cells than did control blastocysts (Table 1). In addition, freshly flushed day 5 blastocysts were cultured overnight in the maximum concentrations of all three inhibitors, and remained fully expanded for at least $24 \mathrm{~h}$ (data not shown).

In view of the above results, additional controls were performed to ensure that the inhibitors could block oxidative phosphorylation in preimplantation embryos. Mouse embryos cultured from the morula stage in $1.0 \mathrm{mmol} \mathrm{KCN}^{-1}$, taken from the same source and prepared in the same manner as for rat morulae, were completely degenerate after $24 \mathrm{~h}$. In control medium, $100 \%$ of mouse morulae formed normal blastocysts (data not shown). All three inhibitors were also tested for their effect on earlier cleavage (two-four-cell) stage rat embryos. In the presence of the maximum concentrations of cyanide, antimycin-A and DNP, the majority of the two- and four-cell embryos degenerated completely within $12-16 \mathrm{~h}$, whereas in 
Table 1. Effects of inhibitors of oxidative phosphorylation on the formation of rat blastocysts in culture

\begin{tabular}{lcccc}
\hline Inhibitor & Concentration & $\begin{array}{c}\text { Number of } \\
\text { morulae }\end{array}$ & $\begin{array}{c}\text { Percentage forming } \\
\text { blastocysts }\end{array}$ & $\begin{array}{c}\text { Blastocyst } \\
\text { cell number }\end{array}$ \\
\hline Cyanide & $0^{\mathrm{a}}$ & 54 & $76 \%$ & $35.6 \pm 1.0(17)$ \\
& 0.01 & 29 & $69 \%$ & $36.8 \pm 1.2(8)$ \\
& 0.10 & 30 & $73 \%$ & $34.9 \pm 1.0(9)$ \\
Antimycin-A & 1.00 & 53 & $62 \%$ & $31.3 \pm 1.2(14)^{\mathrm{d}}$ \\
& $0^{\mathrm{b}}$ & 49 & $69 \%$ & $37.7 \pm 1.7(22)$ \\
& 0.02 & 20 & $80 \%$ & $30.8 \pm 2.0(10)$ \\
2,4-Dinitrophenol & 0.20 & 36 & $73 \%$ & $35.9 \pm 1.5(17)$ \\
& 2.00 & 47 & $72 \%$ & $36.4 \pm 0.9(14)$ \\
& $0^{\mathrm{a}}$ & 27 & $72 \%$ & $36.1 \pm 1.5(15)$ \\
& 0.01 & 34 & $59 \%$ & $34.6 \pm 2.1(11)$ \\
& 0.10 & 47 & $74 \%$ & $23.9 \pm 0.9(9)^{\mathrm{e}}$ \\
\hline
\end{tabular}

Concentration in ${ }^{\mathrm{a}} \mathrm{mmol} \mathrm{l}^{-1} ;{ }^{\mathrm{b}} \mathrm{mg} \mathrm{1^{-1 }}$.

${ }^{c}$ Expressed as mean \pm SEM (number of blastocysts).

Significantly different from control, ${ }^{\mathrm{d}} P<0.05 ;{ }^{e} P<0.001$.

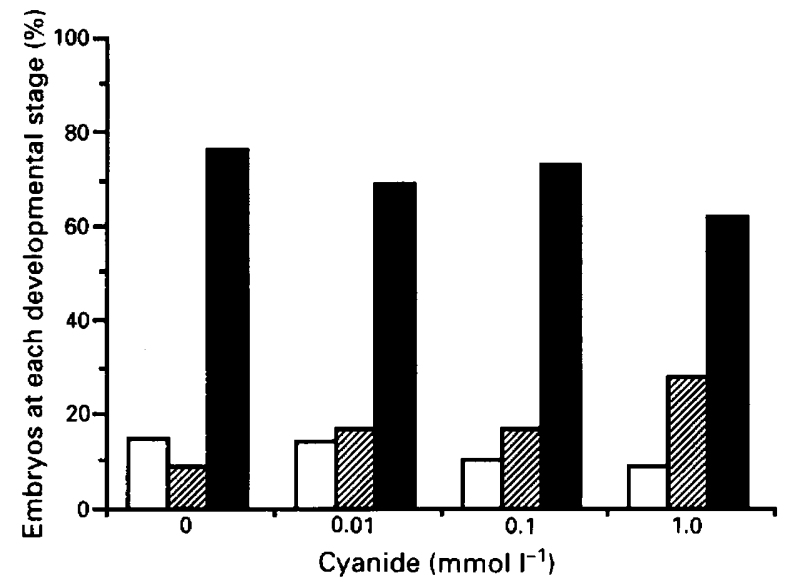

Fig. 1. The percentage of rat morulae reaching each developmental stage ( $\square$ morula, $\square$ early blastocyst, $\square$ expanded blastocyst), after $24 \mathrm{~h}$ culture in control medium (0) and various concentrations of cyanide. Each culture experiment was caried out between three and five times, and similar results were obtained for each replicate, which were then pooled. There were no significant differences in the proportion of embryos developing in the different concentrations of cyanide.

control T6, all the embryos had normal morphology for $36 \mathrm{~h}$ in culture, often undergoing one cleavage division (data not shown).

\section{Glucose consumption and lactate production}

The mechanism by which the rat embryo could form a blastocoel in the presence of inhibitors of oxidative phosphorylation was investigated by examining the effect of cyanide and DNP on the glycolytic capacity of the embryo (Fig. 2). Single, freshly flushed day 5 blastocysts cultured for $2 \mathrm{~h}$ in T6 consumed large amounts of glucose $(34.2 \pm 1.0 \mathrm{pmol}$ per

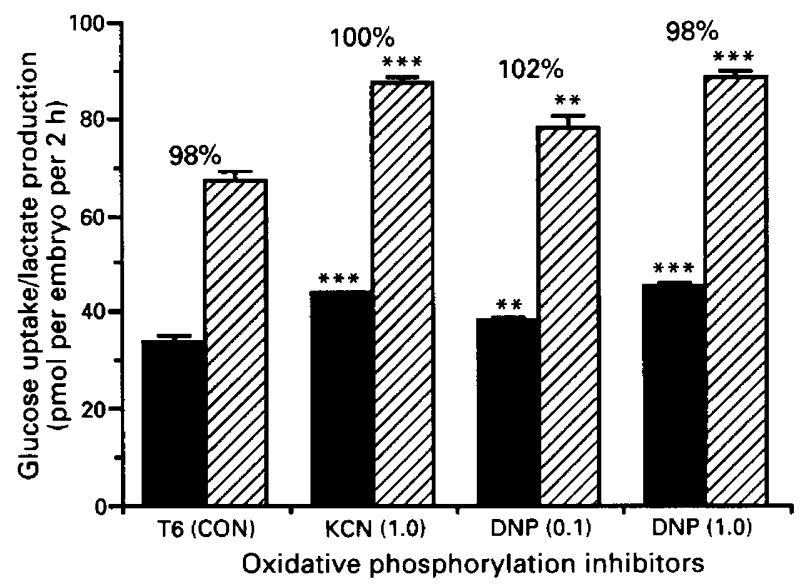

Fig. 2. Glucose uptake ( $\square$ ) and lactate production (囫) by single rat blastocysts cultured in control medium (T6 (CON)), 1 mmol potassium cyanide $1^{-1}(\mathrm{KCN}(1.0))$, and 0.1 and $1.0 \mathrm{mmol} 2,4$-dinitrophenol $1^{-1}$ (DNP(0.1) and DNP(1.0), respectively). Each bar represents the mean \pm SEM of 18 measurements on 18 blastocysts. Experiments were carried out three times, with six blastocysts per experiment. Differences between control and experimental values were tested for statistical significance using Student's $t$ test, and indicated: $* * P<0.01$, $* * * P<0.001$. The figures over the bars represent the percentage of glucose consumption accountable for by lactate production.

embryo per $2 \mathrm{~h}$ ), nearly all of which was accountable for by lactate production $(67.0 \pm 2.0 \mathrm{pmol}$ per embryo per $2 \mathrm{~h})$ into the medium, indicating a substantial capacity for glycolysis, as reported by Brison and Leese (1991). However, at concentrations of $1.0 \mathrm{mmol} \mathrm{l}^{-1}$, both cyanide and DNP significantly $(P<0.001)$ stimulated glucose consumption and lactate production above this already high basal level, by approximately $30 \%$. DNP $\left(0.1 \mathrm{mmol}^{-1}\right)$ also caused a significant $(P<0.01)$, stimulation (about $10-15 \%$ ) of both glucose consumption and lactate production. The percentage of glucose consumption 
accountable for by lactate production was consistently close to $100 \%$, as observed by Brison and Leese (1991).

\section{Discussion}

These results provide strong evidence that oxidative phosphorylation is not obligatory for blastocyst formation in rats. Large numbers of blastocysts with normal morphology formed in concentrations of inhibitors that are completely toxic to mouse embryos, and to earlier cleavage stage rat embryos. This is a striking finding, since the transition from morula to blastocyst is a time of high ATP requirement, primarily due to the functioning of the $\mathrm{Na}^{+}-\mathrm{K}^{+}$-ATPase, which actively transports $\mathrm{Na}^{+}$ions and is implicated in blastocoel cavity formation (Biggers et al., 1988; Leese, 1991). Mouse and rabbit embryos are known to depend on oxidative phosphorylation, as cyanide and DNP are both highly toxic to their development. Thomson (1967) found that two-cell mouse embryos degenerated completely in the presence of $1.0 \mathrm{mmol}$ cyanide $\mathrm{l}^{-1}$, and in $0.1 \mathrm{mmol} \mathrm{I}^{-1}$ formed fewer blastocysts than did controls; $1.0 \mathrm{mmol}$ cyanide $1^{-1}$ also caused $100 \%$ of expanded blastocysts to collapse completely, whereas a less marked effect was seen at a concentration of $0.1 \mathrm{mmol}^{-1}$. DNP caused degeneration of two-cell embryos at concentrations of $0.1 \mathrm{mmol} \mathrm{l}^{-1}$ and above, and when added at $1.0 \mathrm{mmol} \mathrm{l}^{-1}$ to expanded blastocysts caused almost all of them to collapse. Kane and Buckley (1977) found similar effects on one-cell rabbit embryos: 0.1 and $1.0 \mathrm{mmol}$ cyanide $1^{-1}$, and $1.0 \mathrm{mmol}$ DNP $\mathrm{l}^{-1}$ completely inhibited growth to blastocysts. $0.1 \mathrm{mmol}$ DNP $\mathrm{I}^{-1}$ also caused a significant reduction in the rate of development.

Thus, sensitivity to inhibitors of oxidative phosphorylation seems to be specific both to species and developmental stage. Mouse embryos are sensitive throughout the preimplantation period, whereas rat embryos are sensitive only at the earlier stages, becoming much less so during blastocyst formation and expansion. This may be explained in terms of the consumption of exogenous energy substrates. Mouse embryos at early cleavage stages take up little glucose, but large amounts of exogenous pyruvate, which is oxidized via the TCA cycle and oxidative phosphorylation (Brinster, 1967b; Leese and Barton, 1984). The pattern is reversed with development, such that blastocysts take up very little pyruvate, but large amounts of glucose (Leese and Barton, 1984). This switch in substrate preference also occurs in the rat embryo, although cleavage stages before the eight-cell stage were not studied (Brison and Leese, 1991). This finding suggests that oxidative phosphorylation is important early in preimplantation development, in both mice and rats, and this is confirmed by the observation that inhibitors of oxidative phosphorylation are toxic to early mouse (Thomson, 1967) and rat (the present study) embryos. However, by the time of blastocoel cavity formation, while the mouse embryo is still absolutely dependent on oxidative phosphorylation, the rat embryo is much less so. This is presumably a result of the ability of the rat embryo to consume much greater amounts of exogenous glucose than does the mouse embryo, even though the embryos are of similar size, and to produce much greater quantities of lactate from the glucose consumed (Brison and Leese, 1991). The capacity of the rat embryo to generate ATP via glycolysis during blasto- coel cavity formation is therefore much greater than that of the mouse embryo.

This hypothesis is further substantiated by the finding that cyanide and DNP both stimulate the glycolytic capacity of the rat blastocyst. This suggests a possible adaptive mechanism by which the rat embryo might compensate for the loss of ATP via oxidative phosphorylation, i.e. by increasing the rate of glycolysis. The results reported here do not completely preclude a role for oxidative phosphorylation during normal blastocoel cavity formation, but suggest that the embryo is flexible with respect to energy generating pathways and can adapt to changes in its environment.

The changes in the maternal environment experienced by the rat embryo during preimplantation development correlate well with this pattern of energy metabolism. The earlier cleavage stages, up until that of the morula on mid-day 4 , take place in the relatively aerobic environment of the oviduct (Leese, 1988; Fischer and Bavister, 1993). This phase is characterized by a high rate of embryonic pyruvate consumption (Brison and Leese, 1991) and a reliance on oxidative phosphorylation. The enzyme lactate dehydrogenase $(\mathrm{LDH})$, which catalyses the interconversion of lactate and pyruvate, is expressed as its aerobic-type isoenzyme LDH-1 at this stage of development (Brinster, 1979; Leese, 1991). During the morula to blastocyst transition, the embryo passes into the uterus, where the endometrial layers are closely apposed and the volume of uterine fluid is minimal (Enders and Schlafke, 1967; Leese, 1989). The oxygen tension in the uterine lumen may be reduced during the peri-implantation period (Fischer and Bavister, 1993), and during subsequent implantation, the uterine decidual zone in the rat is devoid of capillaries (Krehbiel, 1937; Rogers and Gannon, 1981), and presumably anoxic (Leese, 1989). The pattern of LDH expression switches to the anaerobic isoenzyme LDH-5 in the implanting blastocyst (Brinster, 1979; Leese, 1991). This second phase of preimplantation development is characterized by a low rate of pyruvate consumption, a high rate of glucose consumption and glycolysis (Brison and Leese, 1991), and a potential independence from oxidative phosphorylation. This pattern persists through the immediate postimplantation stages (Clough and Whittingham, 1983; Ellington, 1987) until the maternal circulation to the embryo is established.

Data from this and previous studies indicate that there are species differences in the pattern of energy metabolism during preimplantation development. This work has important implications for our understanding of early human development, as preimplantation human embryos consume glucose in similar amounts (on a per volume basis) to rat embryos, and have a similarly high capacity for lactate production (Gott et al., 1990; Leese et al., 1993).

This work was supported by a post-doctoral fellowship from the Journal of Reproduction and Fertility (D. R. Brison).

\section{References}

Benos DJ and Balaban RS (1980) Energy requirements of the developing mammalian blastocyst for active ion transport Biology of Reproduction $\mathbf{2 3}$ 941-947 
Benos DJ and Balaban RS (1983) Energy metabolism of preimplantation mammalian blastocysts American Journal Physiology 245 C40-C45

Biggers JD and Stern S (1973) Metabolism of the preimplantation mammalian embryo Advances in Reproductive Physiology 6 I-59

Biggers JD, Bell JE and Benos DJ (1988) Mammalian blastocyst: transport functions in a developing epithelium American Joumal of Physiology 255 $\mathrm{C} 419-\mathrm{C} 432$

Brinster RL (1967a) Carbon dioxide production from glucose by the preimplantation mouse embryo Experimental Cell Research 47 271-277

Brinster RL (1967b) Carbon dioxide production from lactate and pyruvate by the preimplantation mouse embryo Experimental Cell Research 47 634-637

Brinster RL (1979) Isozymic analyses of early mammalian embryogenesis Isozymes: Current Topics in Biological and Medical Research 3 155-184

Brison DR and Leese HJ (1991) Energy metabolism in late preimplantation rat embryos Journal of Reproduction and Fertility 93 245-251

Brison DR and Leese HJ (1993) Role of chloride transport in the development of the rat blastocyst Biology of Reproduction 48 692-702

Clough JR and Whittingham DG (1983) Metabolism of ${ }^{14} \mathrm{C}$ glucose by postimplantation mouse embryos in vitro Journal of Embryology and Experimental Morphology 74 133-142

Dufrasnes E, Vanderheyden I, Robin D, Delcourt J, Pampfer S and De Hertogh R (1993) Glucose and pyruvate metabolism in preimplantation blastocysts from normal and diabetic rats Journal of Reproduction and Fertility 98 169-177

Ellington SKL (1987) In vitro analysis in glucose metabolism and embryonic growth in post-implantation rat embryos Development 100 431-439

Enders AC and Schlafke S (1967) A morphological analysis of the early implantation stages in the rat American Journal of Anatomy 120 185-226

Fischer B and Bavister BD (1993) Oxygen tension in the oviduct and uterus of rhesus monkeys, hamsters and rabbits Journal of Reproduction and Fertility 99 673-679

Gardner DK and Leese HJ (1990) Concentrations of nutrients in mouse oviduct fluid and their effects on embryo development and metabolism in vitro Journal of Reproduction and Fertitity 88 361-368

Gardner DK and Sakkas D (1993) Mouse embryo cleavage, metabolism and viability: role of medium composition Human Reproduction 8 288-295

Gauthier T, Denis-Pouxviel C and Murat JC (1990) Respiration of mitochondria isolated from differentiated and undifferentiated HT29 colon cancer cells in the presence of various substrates and ADP generating systems International Journal of Biochemistry 22 411-417

Gott AL, Hardy K, Winston RML and Leese HJ (1990) Non-invasive measurement of glucose and pyruvate uptake by individual human oocytes and preimplantation embryos Human Reproduction 5 104-108
Handyside AH and Hunter S (1984) A rapid procedure for visualising the inner cell mass and trophectoderm nuclei of mouse blastocysts in situ using polynucleotide-specific fluorochromes Journal of Experimental Zoology 231 $429-434$

Kane MT and Buckley NJ (1977) The effects of inhibitors of energy metabolism on the growth of one-cell rabbit ova to blastocysts in vitro Joumal of Reproduction and Fertility 49 261-266

Krehbiel RH (1937) Cytological studies of the decidual reaction in the rat during early pregnancy and in the production of deciduoma Physiological Zoology 10 212-234

Leese HJ (1988) The formation and function of oviduct fluid Joumal of Reproduction and Fertility 82 843-856

Leese HJ (1989) Energy metabolism of the blastocyst and uterus at implantation. In Blastocyst Implantation, pp 39-44 Ed. K Yoshinaga. Adams, New York

Leese HJ (1991) Metabolism of the preimplantation mammalian embryo Oxford Reviews of Reproductive Biology 13 35-72

Leese HJ and Barton AM (1984) Pyruvate and glucose uptake by mouse ova and preimplantation embryos Journal of Reproduction and Fertility 72 9-13

Leese HJ, Conaghan J, Martin KL and Hardy K (1993) Early human embryo metabolism BioEssays 15 259-264

Rogers PAW and Gannon BJ (1981) The vascular and microvascular anatomy of the rat uterus during the estrous cycle Australian Joumal of Experimental Biological and Medical Science $59667-679$

Slater EC (1963) Uncouplers and inhibitors of oxidative phosphorylation. In Metabolic Inhibitors, Vol. II pp 503-516 Eds RM Hochster and JH Quastel. Academic Press, New York

Slater EC (1967) Application of inhibitors and uncouplers for a study of oxidative phosphorylation Methods in Enzymology 10 48-57

Thomson JL (1967) Effect of inhibitors of carbohydrate metabolism on the development of preimplantation mouse embryos Experimental Cell Research 46 252-262

Wales RG (1969) Accumulation of carboxylic acids from glucose by the preimplantation mouse embryo Australian Joumal of Biological Sciences 22 701-707

Whittingham DG (1971) Culture of mouse ova Journal of Reproduction and Fertility 14 7-21

Wood MJ and Whittingham DG (1981) Low temperature storage of rat embryos. In Frozen Storage of Laboratory Animals, pp 119-128 Ed. GH Zeilmaker. Gustav Fischer Verlag, Stuttgart 